\title{
ESTUDO COMPARATIVO DAS ARGILAS DE ROCHAS MESOZOICAS E CENOZOICAS DA DEPRESSÃO CENTRAL DO RIO GRANDE DO SUL
}

\section{Pericles Veiga}

Departamento de Geociências. Centro de Ciências Naturais e Exatas. UFSM. Santa Maria, RS.

\section{RESUMO}

Anālises por difratometria de raios $X$ permitiram comparar a natureza dos argilominerais de rochas mesozóicas da Depressão Cen tral do Rio Grande do Sul (Formação Rosārio do Sul., Formação Santa Maria, e Membro Caturrita da Formação Botucatu) com aqueles de rochas cenozōicas (Terciārio ?) que capeiam parcialmente as primeiras.

Nas rochas mesozóicas predomina a montmorilonita, seguida da ilita e da camada mixta I-M(10-14M). Nos sedimentos cenozóicos, por outro lado, há total predomỉnio da caolinita, com pequenas per centagens de ilita, camada mixta I-M(10-14M) e montmorilonita.

Esta diferença auxilia na distinção das duas seqüências, nos locais onde as litologias são semelhantes. 0 predomínio de montmo rilonita no Mesozóico e o de caolinita no Cenozóico pode ser explí cado por diferença climātica e/ou outros fatores. No caso de diferen ça climātica, o Cenozōico teria sido bem mais ümido que o Mesozōico.

\section{SUMMARY}

VEIGA,P., 1979. Comparative study of the clay minerals of Mesozoic and Cenozoic rocks from the Central Depression of the Rio Grande do Sul State, Brazil.Ciência e Natura (1): 67-77.

Analysis by $x$-ray diffractometry permited to compare the nature of the clay minerals of Mesozoic rocks from the Central Depres sion of the Rio Grande do Sul State, Brazil (Rosārio doSul Formation, Santa Maria Formation and Caturrita Member of the Botucatu Formation) with those of Cenozoic rocks (Tertiary ?) which partially cover the first ones.

In the Mesozoic rocks predominates the montmorillonite, fol lowed by illite and by mixed-layer I-M(10-14M). On other hand, in Ce nozoic rocks there is a complete predomination of kaolinite, with $1 \underline{i}$ tle percentage of $i 11$ ite, mixed-layer $I-M(10-14 M)$ and montmorillonite.

This difference helps in the distinction between the two sequences, in places where the litologies are not fully conclusive. The predominance of montmorillonite in the Mesozoic and kaolinite in the Cenozoic can be explained by climatic differences and/or by others 
causes. In the case of climatic differences, the Cenozoic would have been much more wet than the Mesozoic.

INTRODUÇÃO

A ārea abrangida por este trabalho situa-se na Depressão Central do Estado do Rio Grande do Sul (Figura 1) onde afloram ro chas paleozóicas e mesozóicas do Gondwana brasileiro. A sequéncia me sozóica predomina em extensão ao longo da porção centro-norte desta faixa e sua estratigrafia ainda não foi bem definida.

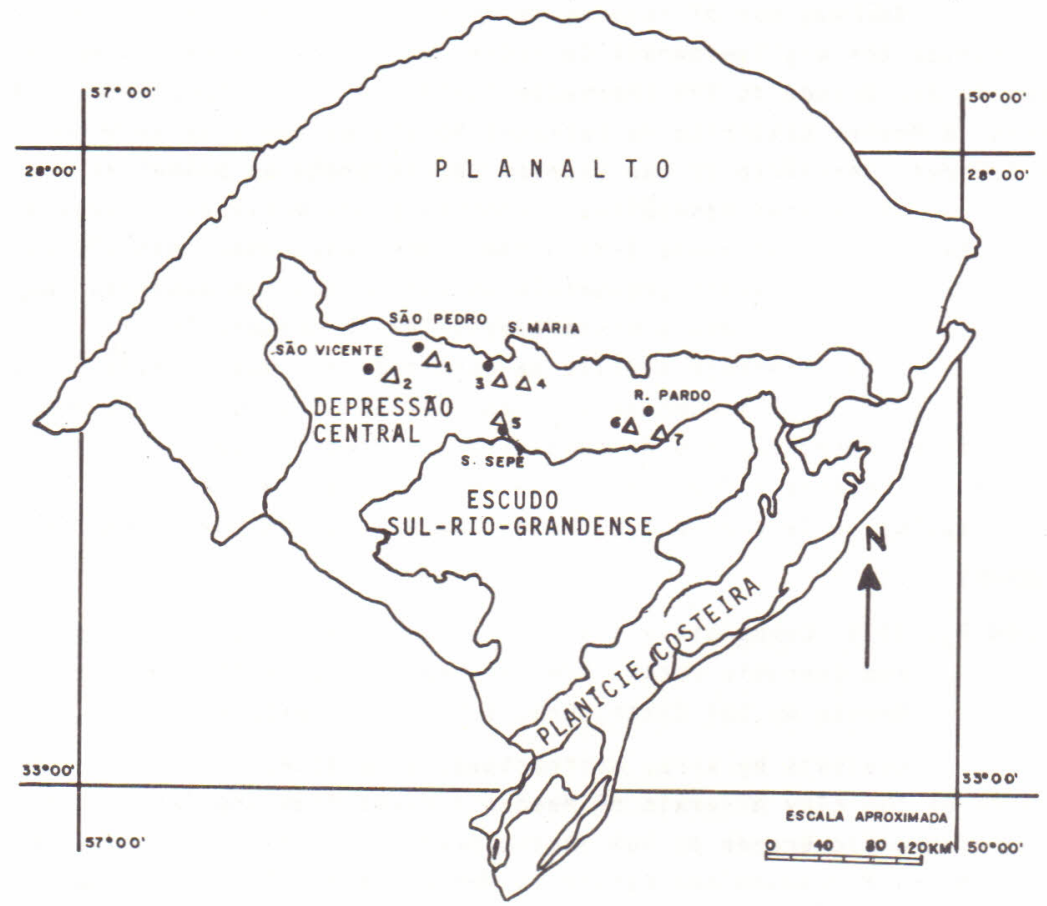

Figura 1. Mapa de localização das amostras.

0 pacote de sedimentos mesozóicos inicia com as litologias de natureza fluvial acentadas sobre a Formação Estrada Nova(Permia no) e termina com os arenitos eōlicos da Formação Botucatu, que no topo se intercalam com os derrames de rochas vulcānicas da Forma ção Serra Geral (Cretāceo).

A sequência fluvial (red beds) intercalada entre a Forma ção Estrada Nova e os arenitos eólicos da Formação Botucatu foi cor relacionada à Formação Rio do Rasto (WHITE, 17) do Grupo Passa Dois e sua parte superior posteriormente elevada a categoriade Formação, 
com o nome de Santa Maria, por GORDON JUNIOR(9) e incluĩda no Grupo São Bento. Mais tarde GAMERMANN(8) denominou Formação Rosārio do Sul a todo o pacote de red beds considerendo a Formação Santa Maria como uma fācies.

Por último, BORTOLUZZI(1) dividiu essa mesma coluna em For mação Rosārio do Sul (na base) com predominnio de arenitos e siltitos bem litificados, Formação Santa Maria (parte média) com uma fácies in ferior arenosa e outrasuperior silto-argilosa e MembroCaturrita (par te superior) constituido de arenitos e siltitos tipicamente fluviais que incluiu na Formação Botucatu.

Tendo em vista que ainda não há um consenso na aceitação de uma ou outra destas proposições, 0 uso dessa nomenclatura gera certa confusão quando não é citada a coluna adotada. Nesse trabalho foi usada a nomenclatura dada por BORTOLUZZI(1), embora acreditemos que não seja a definitiva.

Sobre essa sequência mesozöica da Depressão Central ocor rem sedimentos fluviais cenozóicos (Terciārio ?) que estamos estudan do detalhadamente (Tese de Doutorado).

Considerando que essas duas sequências (Mesozóicas e Ceno zóica) são, predominantemente, de ambiente fluvial e que a primeira, em muitos casos, serviu de fonte para a segunda, é comum a presença de litologias e estruturas semelhantes. Isto torna necessário a pro cura de outros parâmetros que possam tambēm auxiliar na individual $\underline{i}$ zação dessas duas sequências.

Assim, partindo do princípio que rochas semelhantes, mas de idades diferentes, podem apresentar assemblēiasde argilominerais distintas, em função do tipo de clima reinante durante sua deposição ou do ma terial-fonte, decidimos estudar os grupos de argilominerais que ocor rem nas duas sequências, com finalidade de detectar possiveis variá ções.

\section{MATERIAL E METODO}

0 método escolnido para a determinação dos argilominerais foi o da difração de raios $X$ que é o mais usado para esta finalidade.

Do material, inicialmente desagregado em gral de porcela na, foi separada por sedimentação a fração menor que 2 micra, com a adição de exametafosfato de sōdio (calgon) como agente dispersante.

Em seguida foram preparadas duas lâminas orientadas de ca da amostra, secadas ao ar livre, uma para os difratogramas da amos tra natural e glicolada e outro para o difratograma da amostra calci nada a $390^{\circ} \mathrm{C}$.

0 equipamento usado foi um difratômetro marca PHILIPS No RELCO com tubo $35 \mathrm{KV}$ e $20 \mathrm{~mA}$, com filtro de $\mathrm{Ni}$, existente no Institu 
to de Geociências da UFRGS. Os difratogramas atingiram até $30^{\circ}$ à velo cidade de $2^{\circ}$ por minuto.

$\mathrm{Na}$ conversão do ângulo $2 \theta$ em distância interplanar dada em $\AA$, empregou-se a tabela FANG \& BLOSS(7), e a identificaçãodos ar gilominerais foi baseada em BROWN(2), MILLOT(12) e RAMOS \& FORMOSO (13).

Segundo esses autores a caolinita apresenta o pico (001) nas proximidades de $7,15 \AA$ e $0(002)$ a $3,58 \AA$, os quais desaparecem no difratograma da amostra calcinada.

A montmorilonita (esmectita), por outro lado, mostra a re flexão basal (001) entre 12 e $15 \AA$ no difratigrama da amostra natu ral; no caso da amostra glicolada esse pico situa-se nas proximidades de $17 \AA$, enquanto que no difratograma da amostra calcinada o mesmo cai para aproximadamente $10 \AA$.

A ilita apresenta, no difratograma da amostra natural, o pico (001) bem desenvolvido a $10 \AA$ que permanece na glicolada e se reduz ligeiramente na calcinada.

A clorita registra um pico principal (001) a $14 \AA$ e outro secundārio a $7 \AA$ que permanecem na calcinação, alēm dos picos (001) e (003) a 3,51 e 4,7 $\AA$, respectivamente. Quando a clorita é rica em ferro, os picos de 14 e $4,7 \AA$ são de pouca intensidade o que pode ge rar dūvidas na sua identificação. Neste caso a identificação entre clorita rica em Fe e caolinita, segundo RAMOS e FORMOSO(13), pode ser feita através do pico (004) da clorita a $3,51 \AA$ e o (002) da caoli nita a $3,58 \AA$.

A camada mixta irregular formada por ilita intercalada com montmorilonita é chamada I-M ou 10-14M e seu pico (001) pode estar mais prōximo da ilita ou mais prōximo da montmorilonita, is to é, po de aparecer entre 11 e $13 \AA$, dependendo do percentual destes argilo minerais.

No caso de apresentar maior percentual de montmorilonita, pode ser confundida com a mesma; no entanto, no difratograma da amos tra glicolada, o pico desta camada mixta nunca alcança mais de $16 \AA$.

RESULTADOS

De um total de 23 amostras coletadas, 12 corresponderam a rochas cenozóicas típicas (Terciārio?) e 11 a rochas sedimentares do Mesozóico (Formações Rosārio do Sul, Santa Maria e Membro da Catur rita). Esta coleta foi realizada de preferēncia em locais onde aflo ram as duas sequências nos municípios de São Pedro do Sul, Santa Ma ria, São Sepē e Rio Pardo (Figura 1).

$\mathrm{Na} F a z e n d a$ Verde em São Sepé, foi feita uma amostragemver tical (Figura 2) com a finalidade de se verificar o comportamento 


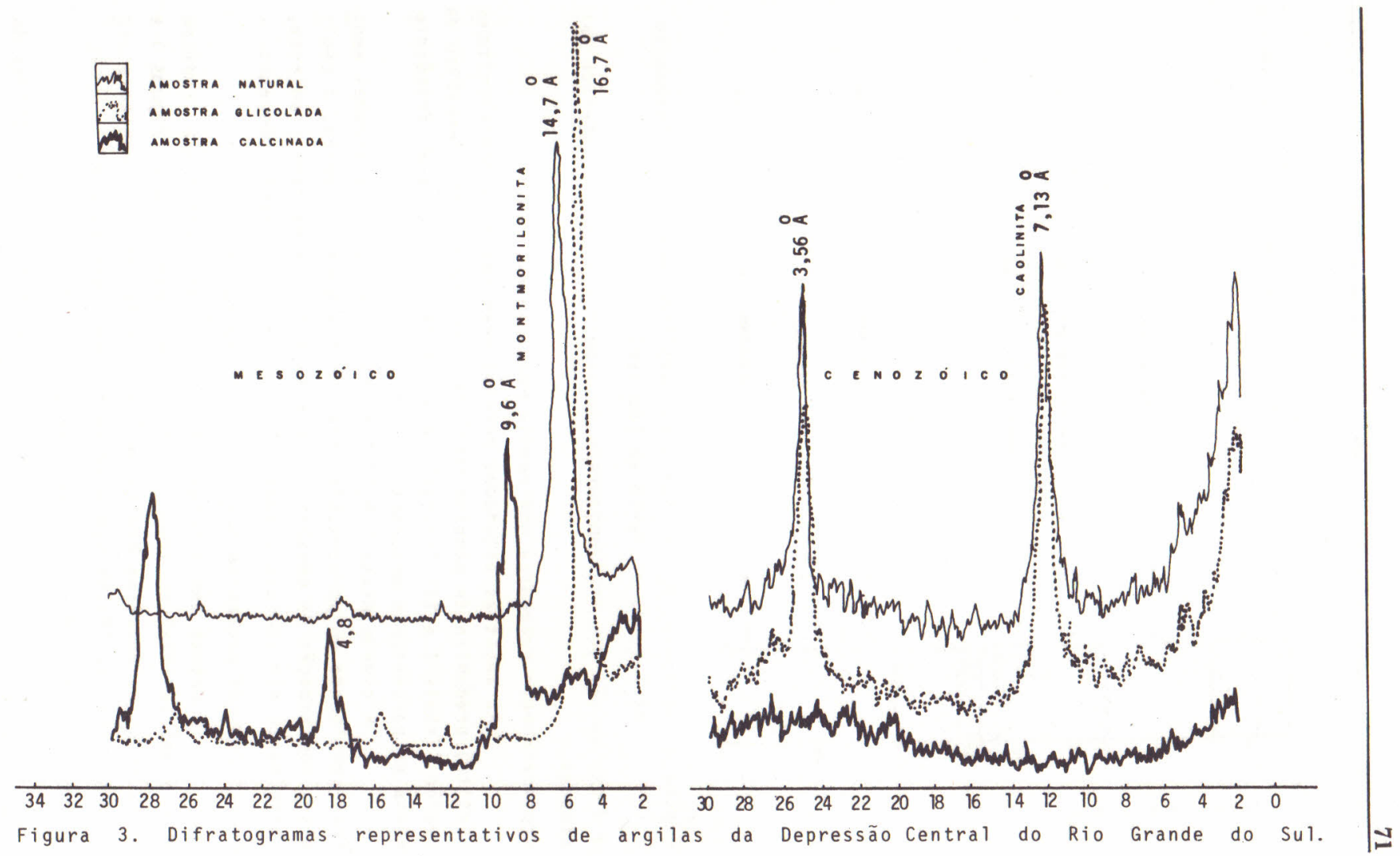




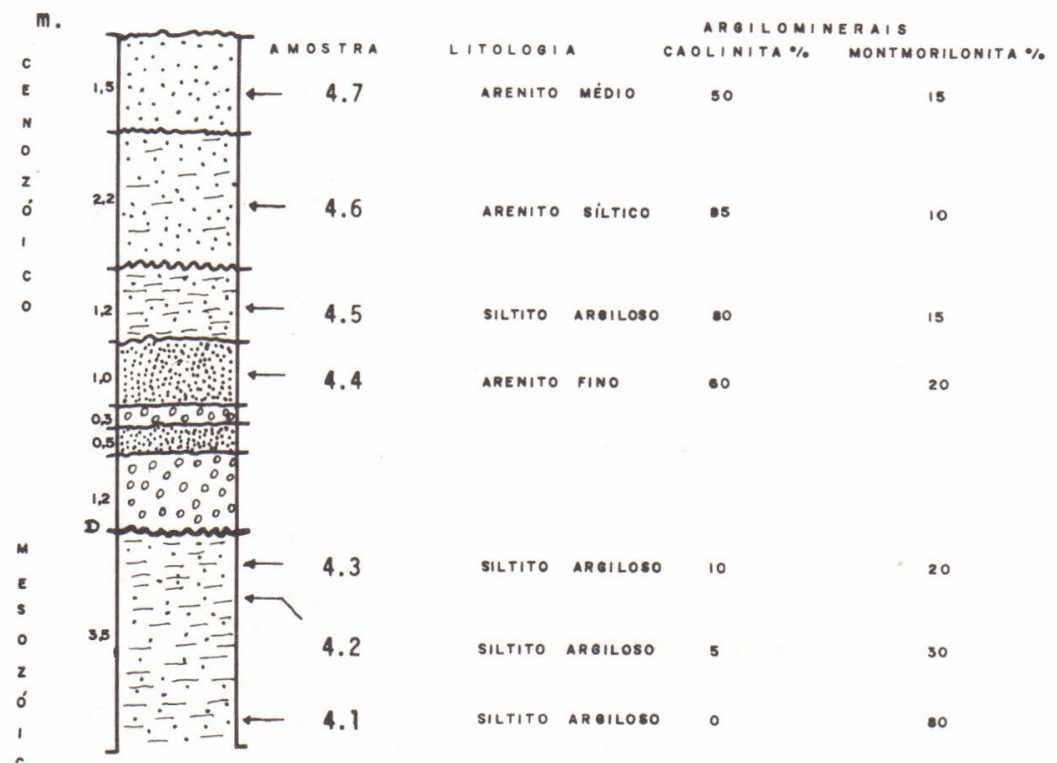

Figura 2. Variação, na vertical, dos argilominerais no afloramento da Fazenda do Verde em São Sepé.

e distribuição dos argilominerais da superfície para o interior das camadas.

Argilominerais presentes nas rochas mesozóicas.

As amostras estudadas demonstraram que a montmorilonitales mectita) predomina de maneira absoluta nas rochas do Mesozóico da região (Tabela I e II; Figuras 3 e 4 ). A ilinita aparece frequlente mente em percentuais pequenos.

A camada mixta I-M(10-14M) foi localizada em algumas amos tras geralmente em percentuais inferiores a montmorilonita. A caoli nita, com exceção da amostra 6.2 que serā discutida mais adiante, normalmente não aparece e quando o faz è em percentuais pequenos.

Argilominerais presentes nos sedimentos cenozóicos.

0 estudo dos difratogramas das rochas cenozöicas indicam um predominio total do grupo da caolinita (Tabela I e II, Figuras 3 e 4 ) em todas as amostras analizadas. A ilinita, montmorilonita e in terestratificado $10-14 \mathrm{M}$ aparecem em pequenas quantidades.

Variaço dos argizominerais na vertical.

0 perfil vertical amostrado numa camada silto-argilosa da Formação Rosārio do Sul, na Fazenda do Verde em São Sepē,demonstrou 
TABELA I. GRUPOS DE ARGILOMINERAIS, EM PARTES POR 10, DE ROCHAS SE DIMENTARES CENOZOICAS E MESOZOICAS DA DEPRESSAO CENTRAL DO RIO GRANDE DO SUL.

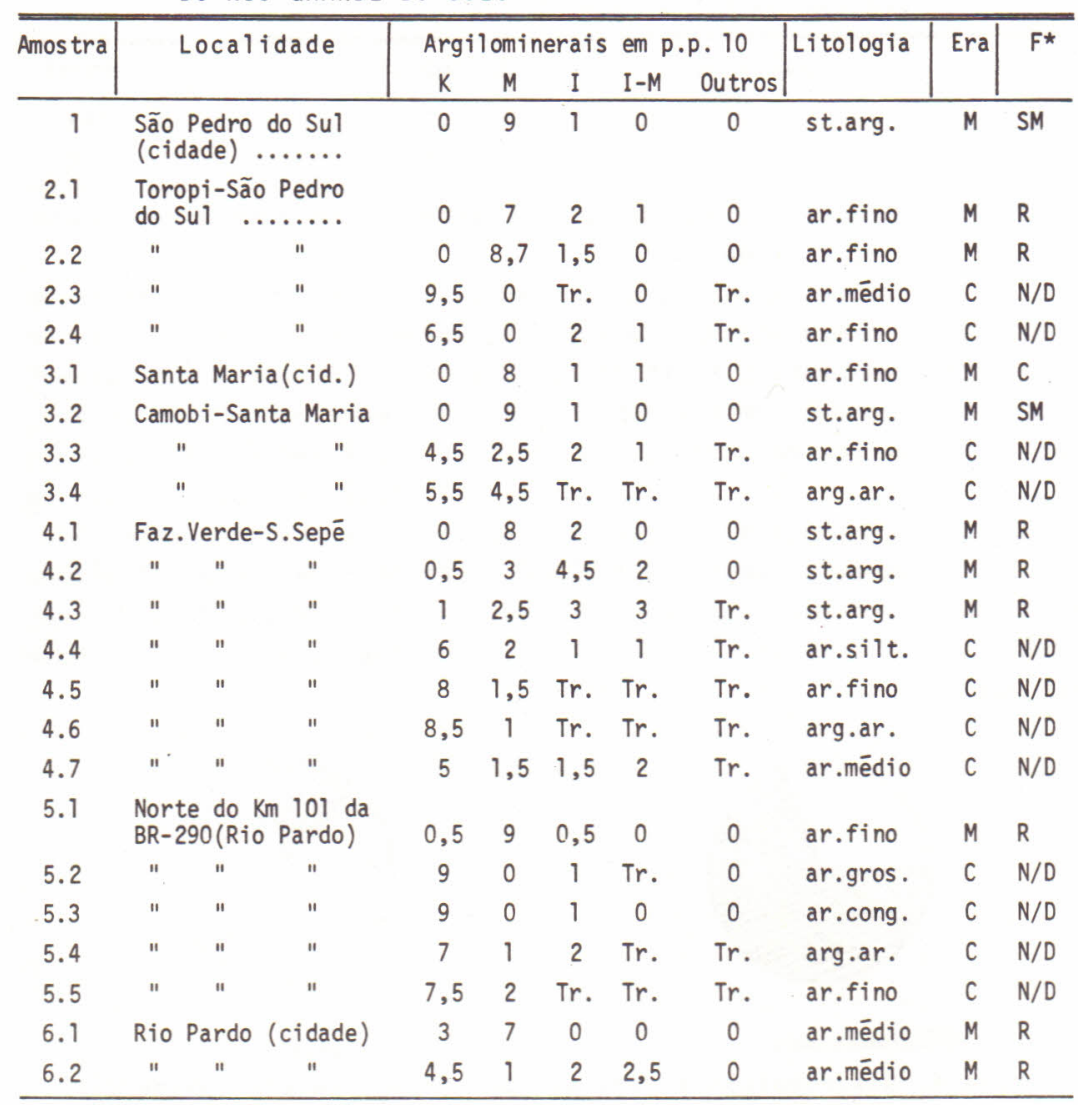

Simbologia: (K) caolinita; (M) montmorilonita; (I) ilita; (I-M)camada mixta ilita-montmorilonita.

Congl.- conglomerado; ar.- arenito; aren.- arenoso;st.siltito; silt.- siltico; arg.- argilito; argil.-argiloso.

que a caolinita existente nesta camada mesozóica decresce da superfí cie (contato discordante com as rochas cenozōicas) para o interior(ba se), atē desaparecer totalmente na profundidade inferior a 3 metros. Assim, a amostra 4.3, extraîda a $0,5 \mathrm{~m}$, abaixo da discordância, apre sentou $10 \%$ de caolinita; a amostra 4.2 , retirada a 1 m, abaixo da mes ma discordāncia, apresentou apenas $5 \%$, aproximadamente, de caolinita; finalmente, a amostra 4.1 , retirada a $3 \mathrm{~m}$, não registrou a presença de caolinita. Alēm disso, a montmorilonita aumentou progressivamente F* Formação: (SM) Santa Maria, (R) Rosārio; (N/D) Não Descrito; (C) Caturrita. 
TABELA II. PERCENTUAL MEDIO GLOBAL DE MONTMORILONITA E CAOLINITA EM ROCHAS SEDIMENTARES CENOZOICAS E MESOZOICAS DA DEPRESSÃO CENTRAL DO RIO GRANDE DO SUL.

\begin{tabular}{cccc}
\hline Era & Caolinita & Montmorilonita & Outros \\
Cenozōica & $71 \%$ & $13 \%$ & $16 \%$ \\
Mesozóica & $8 \%$ & $65 \%$ & $27 \%$ \\
\hline
\end{tabular}

abaixo da discordância atingindo a 3 metros o seu teor normal nessas rochas, is to é, mais de $70 \%$.

A primeira vista, o fenômeno parece indicar a penetração da caolinita existente nas rochas superiores sobre as inferiores. No entanto, segundo MACIEL FILHO (informação verbal), que vem desenvol vendo pesquisa sobre a obstrução de filtros em barragens, a penetração de argi las em sedimentos mais finos que arenitos não é verificada na prātị ca e, portanto, é mais conveniente invocar fenôménos pedológicos an teriores a deposição da sequência superior para explicar este fato.

Tambēm as amostras 6.1 e 6.2 , colhidas em arenitos médios permeāveis da Formação Rosārio do Sul, em Rio Pardo, apresentaram per centual relativamente alto de caolinita, o que poderia ser explicado por fenōmeno semelhante ao anterior.

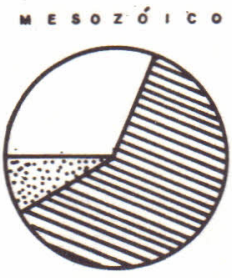

SIS MONTMO RILONTA

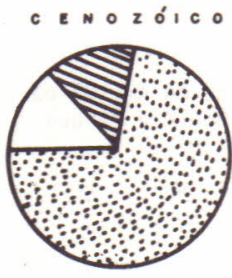

outros

Figura 4. Distribuição percentual dos grupos de argilominerais em sedimentos mesozóicos e cenozóicos da Depressão Central do Rio Grande do Sul.

Em vista do exposto, é evidente que a distinção, pela anā lise de argilas, entre rochas mesozōicas e cenozōicas, das formações estudadas na ārea, ē possível, desde que a amostragem seja ampla, rea lizada em perfís verticais e sempre que possivel em camadas de gra nulometria fina.

\section{DISCUSSÃO}

Como vimos, a montmorilonita predomina claramente nas ro chas mesozóicas, enquanto a caolinita é o argilomineral mais abun dante nas rochas cenozōicas.

o predominio de montmorilonita nas formações superiores da Bacia do Paranā não é fato novo pois BORTOLUZZI(1) encontrou este ar 
gilomineral com percentuais mais altos que os demais em cinco amos tras da Formação Santa Maria. RAMOS \& FORMOSO(13) estudando os arg $\underline{i}$ lominerais da Formação Botucatu, na qual foram incluidas as Formações Rosārio do Sul e Santa Maria, também demonstram que a montmorilonita ē dominante.

Esse predominio da montmorilonita em rochas continentais poderia ser explicado por contribuição vulcânica ou aridez na ārea fonte, jā que normalmente em climas quentes e ümidos hā maior abun dância de caolinita em rochas continentais (MILLOT,12).

Considerando que a Formação Botucatu é constituĩda de are nitos eōicos e que a montmorilonita predomina tambēm nas formações inferiores, inclusive a Rosārio do Sul, ē provāvel que um clima sẹ mi-ārido e finalmente ārido tenha existido na região durante a sedí mentação dessas camadas vermelhas (red beds) no Mesozóico.

Quanto a isso, a idade da Formação Santa Maria do Triāssi co Superior (COLBERT,3) e os arenitos eōlicos intercalados às lavas da Formação Serra Geral na ārea em estudo (VEIGA,15), com idades que atingem o Cretāceo Médio (SARTORI, MACIEL FILHO \& MENEGOTTO,14), sü gerem a predominância da aridez durante quase todo o Mesozóico.

Nos sedimentos cenozóicos se constatou o predomínio da cao linita sobre a montmorilonita, tanto no computo global como conside rando cada localidade em particular (Tabelas I e II).

Sendo a fonte desses sedimentos as rochas subjacentes se dimentares mesozōicas, vulcānicas da Formação Serra Geral e litolo gias do Escudo Sul-rio-grandense, o predomínio absoluto da caolinita sugere uma mudança bastante prununciada no clima do Cenozōico,em re lação ãquele do Mesozōico.

MILLOT(12), estudando a neoformação de argilas e de hidrō xidos nos solos, concluiu que quando o meio é bem drenado, sem len çol freātico permanente, a gibsita acompanhada de goethita, se for ma diretamente pela hidrōlise dos silicitos. Por outro lado, num meio bem drenado, com lençol freātico permanente, o teor de silício em so lução aumenta e permite a neoformação da caolinita.

HARDER(10), sintetizou diferentes espēcies de argilominera is em torno de $20^{\circ} \mathrm{C}$, a partir de soluções diluidas de sỉlica e ōxí dos metālicos, afirmando que para isso ē necessārio ācido silīcico monômero entre 5 e 100 ppm, baixa taxa de precipitação alēm da depen dência da composição dos precipitantes e dos tamanhos dos cātions.

A partir dessa experiência o autor sugere que a formação de argilominerais na natureza depende muito do percentual de $\mathrm{SiO}_{2}$ oqual é muito baixo nas épocas chuvosas dos climas laterizantes (úmidoscom estações secas) e muito alto nas estações secas ou climasāridos com dre 
nagem fechada.

Assim, como não foi constatada a presença de gibsita nos sedimentos da região estudada (apenas o diaspōro em baixas propor ções em duas amostras), o predomínio da caolinita poderia advir de um clima ümido, bem drenado; com lençol freātico permanente, não chê gando a alcançar condições laterizantes.

Para a formação de caolinita em ambientes laterizantes HAR DER(10) sugere certas condições especiais tais como estação menos chuvosa, submerssão e presença de compostos orgānicos em soluções āci das fracas.

E interessante observar, tambēm, que em sedimentos recen tes do Guaíba(5) e da Lagoa dos Patos(16) a montmorilonita é em gé ral o argilomineral dominante, o que nos leva supor a existência de uma diferença climātica entre o Recente e a ēpoca de deposição das rochas cenozóicas (Terciārio?) aqui estudadas.

CONSLUSOES

1. Nas rochas sedimentares mesozóicas estudadas da Depres são Central do Rio Grande do Sul, a montmorilonita (esmectita) é o argilomineral dominante.

2. Nas rochas sedimentares cenozóicas que capeiam parcial mente as rochas mesozóicas, na ārea estudada, existe predomīnio ma cante da caolinita sobre os demais argilominerais.

3. A ilita e a camada mixta ilita-montmorilonita (10-14M) foram encontradas nas duas sequências em pequena percentagem,enquan to a clorita aparece somente em traços.

4. A dominância absoluta da montmorilonita nas rochas flu viais mesozóicas sugere um clima relativamente sêco predominando ao longo dessa Era geolōgica, ao passo que a grande quantidade de cao linita nas rochas cenozóicas estudadas nesse trabalho, na mesma á rea, sugere clima ümido na época de deposição (Terciārio ?).

5. A diferença significativa entre os tipos de argilomine rais dominantes nas duas sequências (montmorilonita no Mesozóico e caolinita no (enozōico) pode ser usada como um parâmetro para dis tingui-las quando as litologias forem semelhantes.

BIBLIOGRAFI A CITADA

1. BORTOLUZZI,C.A. Contribuição ã geologia da região de Santa Maria, Rio Grande do Sul, Brasil. Pesquisas, Porto Alegre, UFRGS, (4): 7-86, 1974 .

2. BROWN,G., Comp. The $X$ Ray identification and structures of clay minerazs. London, Mineralogical Society, 1972, 544p.

3. COLBERT,E.W. A Saurisshian Dinosaur From the Triassic of Brazil. 
Novitates, New York, 2405, p.39, 1970.

4. CORDANI,U,G. \& VANDOROS,P. Basaltic rocks of the Parana basin In: BIGARELLA,J.; BEKER,R.D.; PINTO,I.D. (Edit.) Problems in Brazi Zian Gondwana Geology; Curitiba, P. 207-231, 1967.

5. CUNHA,R. O estuário do Guaíba. Caracteristicas texturais, minera Zógicas e morfológicas. Porto Alegre, Curso de Pōs-Graduaçãoem Geociências, UFRGS, 1971, 51p. (Tese de Mestrado).

6. CUNHA,R. \& FORMOSO,M.L.L. Argilominerais das rochas sedimentares da Bacia de Pelotas-Rio Grande do Sul. In: CONG. BRAS. DE GE LOGIA, 309, 1978. Anais ... Recife. SBG 3:1123-1134.

7. FANG,J.H. \& BLOSS,F.D. X-Ray Difration Tables: Southern Illinois University Press. 1966.

8. GAMERMANN,N. Formação Rosārio do Sul. Pesquisas, Porto Alegre,UE RGS . (2): 5-25, 1973.

9. GORDON Jr.,M. Classification of the Gondwanic rocks of Parana,S. Catarina and Rio Grande do Sul. Notas Preliminarés e Estudos; Departamento Nacional de Produção Mineral, Div. de Geol. e Mi neralogia; Rio de Janeiro, 38: 1-19, 1947.

10. HARDER,H. C.lay mineral formation under lateritic conditions;Clay Minerals 12: 281-288, 1977.

11. MC.DOUGAL, I. \& RUEGG,N.R. Potassium-argon dates on the Serra Ge ral Formation of South America. Geoch. Cosmoch. Acta; 30: 191$195,1966$.

12. MILlOT,C. Geologie des Argiles; Paris, Masson et Cie Editeurs, $1964,499 \mathrm{p}$.

13. RAMOS,A.M. \& FORMOSO,M.L.L. Argizominerais das rochas sedimenta res da Bacia do Paranā. Rio de Janeiro, Petrobrās, 1975, 77p. (Sērie Ciência-Tēcnica-Petrōleo; secção: Exploração de Petrō 1 eo, 9).

14. SARTORI,P.L.P.; MACIEL FILHO,C; MENEGOTTO,E. Contribuição ao es tudo das rochas vulcânicas da Bacia do Paranā na Regiãode San ta Maria, RS. Rev.Bras. de Geologia.São Paulo, 5 (3):141-159, 1975.

15. VEIGA,P. Estudo dos arenitos "intertrapps" da Formacão Serra Ge ral na região de Santa Maria, RS. Porto Alegre, Curso de PōsGraduação em Geociências, UFRGS, 1973, 88p. (Tese de Mestrado).

16. VILLWOCK,J.A. Aspecto da sedimentąão na região nordeste da Lagoa dos Patos: Lagoa do Casamento e Saco do Cocuruto-RS-Brasiz Por to Alegre, Curso de Pōs-Graduação em Geociências, UFRGS, 1973, 88p. (Tese de Mestrado).

17. WHITE,I.C. Relatörio Final da Comissão de Estudos das Minas de Carvão de Pedra do Brasiz. Parte I: Relatōrio sobre as "Coal 
78

Messures" e rochas associadas do Sul do Brasil; Rio de Janei ro, Min. da Ind. Viação e Obras Públicas, 1908, 300p. 